\title{
HUBUNGAN UKURAN DAN KEMAMPUAN MUAT KAPAL PUKAT CINCIN KECIL PADA BEBERAPA DAERAH DI SULAWESI UTARA
}

\author{
(Relationship between boat dimension and loading capacity of small purse-seiner \\ in some areas in North Sulawesi)
}

Revols D. Ch. Pamikiran ${ }^{1}$

${ }^{1}$ Fakultas Perikanan dan Ilmu Kelautan, Universitas Sam Ratulangi, Manado, Sulawesi Utara.

\begin{abstract}
Kapal pukat cincin kecil merupakan kapal ikan yang umum digunakan untuk menangkap ikan pelagis kecil pada beberapa lokasi perairan di Sulawesi Utara. Penelitian ini bertujuan untuk mengetahui hubungan antara sesama dimensi ukuran utama dan antara dimensi ukuran utama dengan kemampuan muat pada 41 sampel kapal pukat cincin yang tersebar di beberapa lokasi di Sulawesi Utara. Hasil penelitian menunjukkan bahwa antara dimensi utama kapal pukat cincin memiliki model persamaan $\mathrm{B}=1,855+1,149 \mathrm{~L}$ dengan $\mathrm{r}=0,74 ; \mathrm{D}=-3,812$ 年9,277L dengan $\mathrm{r}=0,70$, dan hubungan antara panjang (L) dan kapasitas muat (GT) kapal pukat cincin mentruti model persamaan $\mathrm{GT}$ pukat cincin $=2,154 \mathrm{~L}^{0,043 \mathrm{~L}}$ dengan $\mathrm{r}=0,95$.
\end{abstract}

Kata kunci: muatan kotor, kapal pukat cincin, Sulawesi Utara.

Small Purse-Seiner is a fishing vessel which is commonly used in catching small pelagic fish in several locations in North Sulawesi. The purpose of this study was to determine the relationship between the principle dimensions and between principle dimension with loading capacity (Gros Tonnage, GT). This research was conducted on 41 purse seiners from several locations in North Sulawesi. The results showed that relationship between the principle dimensions followed the equation models $\mathrm{B}=1.855+1.149 \mathrm{~L}$, with $\mathrm{r}=0.74 ; \mathrm{D}=-3.817+9.277 \mathrm{~L}$, with $r=0.70$, and the relationship between the length (L) and load capacity (GT) purse seiner is fitted by the following mathematical model: $\mathrm{GT}$ purse seiner $=2.154 \mathrm{~L}^{0.043 \mathrm{~L}}$ with $\mathrm{r}=0.95$.

Keywords: gross tonnage, small purse-seiner, North Sulawesi.

\section{PENDAHULUAN}

Kapal pukat cincin (small purse-seiner) adalah salah satu jenis kapal perikanan yang digunakan pada usaha perikanan tangkap di Provinsi Sulawesi Utara. Sebagai komponen usaha maka ada kewajiban ekonomi yang harts dipenuhi pemilik kapal, dan salah satunya adalah perijinan kapal. Biaya perijinan kapaltergantung pada ukuran kemampuan muat kapat (Gross Tonnage, GT), semakin besar ukuran kapal maka akan semakin tinggi pula biaya perijinan yang harus dibayar. Oleh karena itu pengetahtran dan informasi tentang ukuran kemampuan-muat kapal (GT) baik secara teknis dan ékonomis perlu dimiliki oleh pemilik usaha perikanan dan bahkan berbagai pihak yang membutumkan informasi ini. Berdasarkan hal ini maka perlu dilakukan suatu kajian tentang GT kapal pukat cincin pada beberapa daerah di Sulawesi Utara.

Suhariyanto dan Zarochman (1999), menyatakan bahwa GT merupakan besarnya jumlah volume ruangan tertutup yang dianggap kedap air di dalam kapal ikan. Jadi jumlah besaran volume kapal ikan atau tonnage kapal ikan yang dinyatakan dalam satuan Register Tonnage merupakan GT, sedangkan Net Tonnage (NT) merupakan muatan bersih. Ada 3 metode pengukuran GT kapal yaitu pengukuran dalam negeri, pengukuran internasional, dan pengukuran khusus. Metode pengukuran dalam negeri sebagaimana dilakukan untuk pengukuran dan penentuan tonase kapal yang berukuran panjang kurang dari $24 \mathrm{~m}$, metode pengukuran internasional dilakukan untuk pengukuran dan penentuan tonase kapal yang berukuran panjang $24 \mathrm{~m}$ atau lebih, sedangkan metode pengukuran khusus dilakukan untuk pengukuran dan penentuan tonase kapal yang akan melewati terusan tertentu.

Keputusan Presiden No.5 tahun 1989, dinyatakan bahwa pengukuran tonase kapal yang $\mathrm{u}-$ kuran panjangnya $<24 \mathrm{~m}$, mengikuti petunjuk ukur secara nasional. Pengukuran tonase kapal ikan di Indonesia mengikuti rumusan $\mathrm{GT}=$ volume ruang tertutup $\mathrm{x}$ Register Ton (RT), dimana $\mathrm{RT}=0,353$ (Suhariyanto dan Zarochman, 1999). Untuk kapal yang berukuran panjang $\geq 24 \mathrm{~m}$, mengikuti petunjuk pengukuran secara internasional. Suzuki (1980) menyatakan bahwa berdasarkan konvensi internasional tentang pengukuran kapal (International Convention on Tonnage Measurement of Ships), kapal dengan ukuran panjang $\geq 24 \mathrm{~m}$, GT dihitung berdasarkan rumus: GT=V.K, dimana V sebagai 
volume semua ruang tertutup (di atas dan di bawah dek) dalam satuan $\mathrm{m}^{3}$ dan $\mathrm{K}=0,2+0,02$ Log10 V. Volume ruang tertutup di bawah dek dapat dihitung dengan pendekatan koefisien bentuk kapal dalam hal ini koefisien balok $(\mathrm{Cb})$ berdasarkan rumusan dalam Nomura and Yamazaki (1977) dan telah disesuaikan sebagai berikut: $\mathrm{V}=\mathrm{L} \times \mathrm{B} \times \mathrm{D} \times \mathrm{c}_{\mathrm{b}}$, dimana $\mathrm{L}=$ panjang, $\mathrm{B}=$ lebar, $\mathrm{D}=$ tinggi dek, dan $\mathrm{Cb}=$ koefisien balok kapal sampai dek.

Tujuan dari penelitian ini untuk mengetahui hubungan antara ukuran utama (principle dimension) kapal pukat cincin dan ukuran utama dengan kemampuan muat (GT) kapal pukat cincin pada beberapa lokasi di Sulawesi Utara. Penelitian ini diharapkan dapat memberikan informasi sebagai dasar dalam mengestimasi GT berdasarkan ukuran utama kapal pukat cincin di Sulawesi Utara.

\section{METODE PENELITIAN}

Penelitian ini dilaksanakan di beberapa pusat usaha perikanan pukat cincin di Sulawesi Utara yakni Pelabuhan Perikanan Pantai (PPP) Tumumpa, Pelabuhan Perikanan Samudra (PPS) Bitung dan Tempat Pelelangan Ikan (TPI) Belang. Waktu pelaksanaan pada bulan Januari-Februari 2011. Penelitian ini dilakukan untuk memberi gambaran tentang karakteristik teknis kapal sebagai hasil dari pengukuran dan analisis ukuran utamg dan kemampuan muat kapal pukat cincin ariv1 kapal sampel yang ada pada beberapa lokasi di Sulawesi Utara.

Teknik pengambilan data difakukan melalui pengamatan dan pengukuran for hadap ukuran utama kapal pukat cincin sebaga parameter dalam menghitung GT kapal, dimana ukuran-ukuran tersebut meliputi :

- Bangunan bawah dek:Pånjang (L), yaitu panjang register yang diukur dari ujung buritan hingga bagian ujung tuang tersekat haluan. Lebar (B) yaitu lebar register yang diukur pada bagian tengah kapal yang paling lebar, dan diukur dari sisi kanan ruang sampai sisi kiri ruang yang tersekat. Dalam (D) yaitu tinggi atau dalam register yang drambil pada bagian tengah kapal dan diukur dari ruang tersekat dek terendah sampai ke bagian badan kapal terbawah.

- Bangunan atas dek (superstruktur): Panjang (1), diukur dari depan ruang tersekat sampai bagian belakang ruang tersekat bangunan di atas kapal. Lebar (b), diukur dari sisi kanan sampai sisi kiri ruang tertutup. Tinggi $(\mathrm{t})$, diukur dari ruang tersekat atap sampai ruang tersekat lantai.

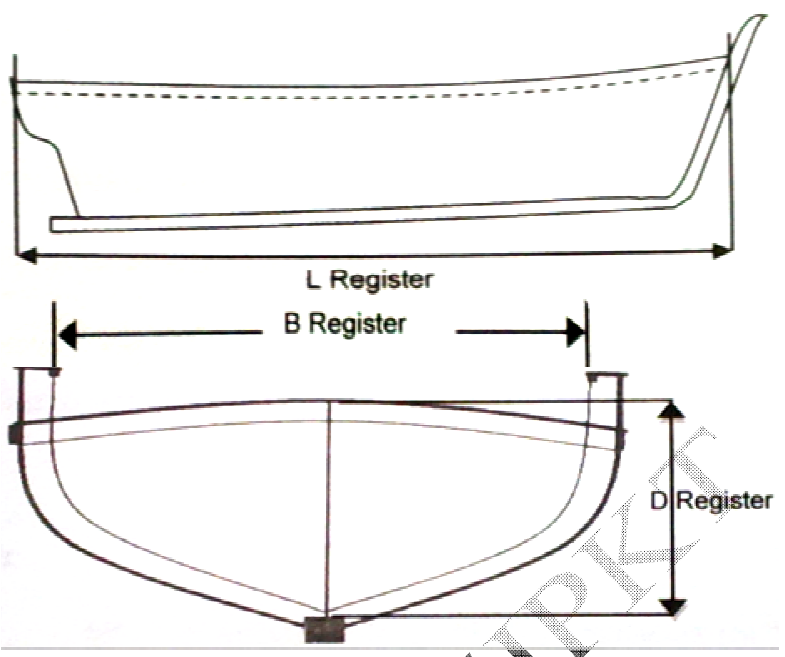

Gambar 1. Pengukuran bangunangdi Wawah dek.

Figure 1. Measurements of the building at below deck.

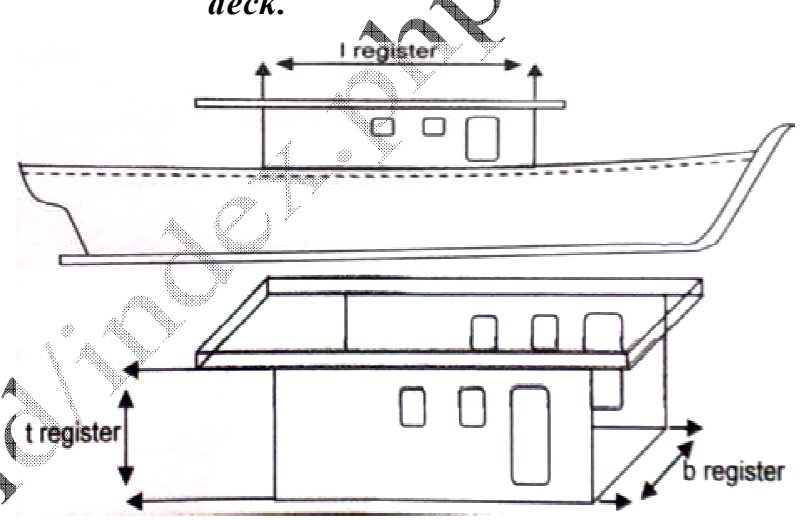

Gambar 2. Pengukuran bangunan atas dek.

Figure 2. Measurements of the building at upper deck.

Ada dua tahap untuk menghitung volume kapal, yaitu volume di bawah dek dan volume di atas dek (superstruktur).

- Volume ruang di bawah dek $\left(\mathrm{V}_{1}\right)$ menggunakan rumusan yang dikemukakan oleh Nomura and Yamazaki (1977) dan telah disesuaikan menjadi:

$$
\mathrm{V}_{1}=\mathrm{L} \times \mathrm{B} \times \mathrm{D} \times \mathrm{c}_{\mathrm{b}}
$$

Nilai $\mathrm{Cb}$ yang digunakan adalah rata-rata nilai $\mathrm{Cb}$ kapal pukat cincin seperti yang dinyatakan dalam Marasut (2006), yaitu 0,56.

- Volume ruang di atas dek $\left(\mathrm{V}_{2}\right)$ menggunakan rumusan yang disesuaikan dengan bentuk ruang, pada penelitian ini bentuk ruang atas dek adalah persegi empat. Dengan demikian maka rumusan volume di atas dek adalah: $\mathrm{V}_{2}=1 \times \mathrm{b} \times \mathrm{t}$, dimana $\mathrm{l}=$ panjang register $(\mathrm{m}) ; \mathrm{b}=$ lebar register $(\mathrm{m})$; $\mathrm{t}=$ tinggi register $(\mathrm{m})$. Untuk menghitung GT kapal menggunakan rumusan $\mathrm{GT}=\left(\mathrm{V}_{1}+\mathrm{V}_{2}\right) \times \mathrm{RT}$, nilai $\mathrm{RT}=0,353$ (Suhariyanto dan Zarochman, 1999).

Analisis hubungan antar ukuran utama yakni antara Panjang (L), Lebar (B) dan Dalam (D) dan hubungan antara ukuran utama kapal dengan GT dilakukan sebagai berikut. Rumusan matematis 
hubungan antara L dan $\mathrm{B}, \mathrm{L}$ dan $\mathrm{D}$, dan L dan GT adalah $y=f(x)$, dimana $x$ adalah variable bebas yakni $\mathrm{L}$ dan y adalah variable tak bebas yakni B, D dan GT. Untuk keperluan analisis dan penggambaran kurva hubungan antar variabel, digunakan aplikasi Curve-Expert 1,4 (Hyams, 2009).

\section{HASIL DAN PEMBAHASAN}

\section{Hubungan antara ukuran utama kapal}

Hasil analisis data terhadap ukuran utama kapal pukat cincin (Tabel 1) sebagai berikut:

- Hubungan antara L dan B mengikuti pola linear dengan model persamaan $\mathrm{B}=1,855+1,149 \mathrm{~L}$, dan $\mathrm{r}=0,74$ (Gambar 3).

- Hubungan antara L dan D mengikuti pola linear dengan model persamaan $\mathrm{D}=-3,817+9,277 \mathrm{~L}$, dan $\mathrm{r}=0,70$ (Gambar 4).

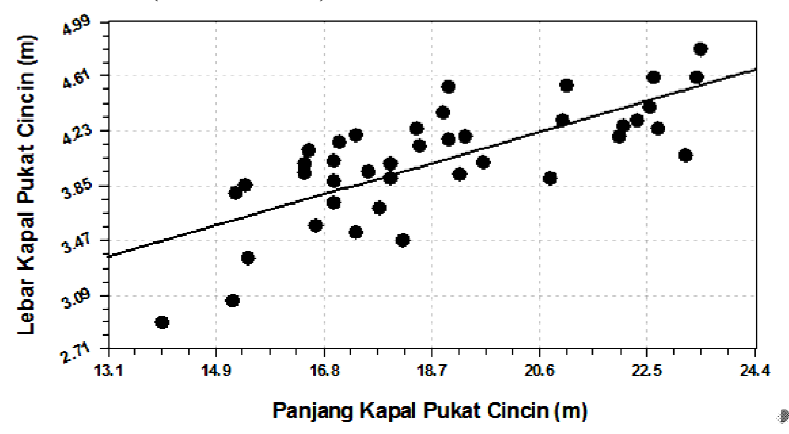

Gambar 3. Hubungan antara Panjang (L) dan Lebar (B) pada kapal pukat cincin kectl.

Figure 3. The relationship between Length (G) and Breath (B) in a small purse seiner.

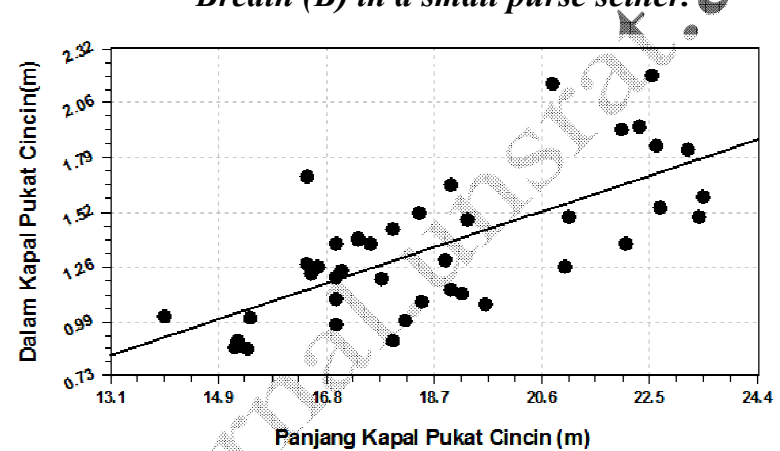

Gambar 4, Fybungan antara Panjang (L) dan DaTâm (D) pada kapal pukat cincin kecil. Figure The relationship between Length $(L)$ and Depth (D) in a small purse seiner.

Adanya hubungan antara L dan B, serta L dan D kapal pukat cincin menunjukan bahwa ada pola bentuk dari kapal pukat cincin yang diteliti baik dalam arah L, B dan D, sehingga dengan demikian hubungan dalam bentuk persamaan matematis dapat digunakan sebagai penduga antar ukuran utama kapal pukat cincin pada beberapa lokasi di Sulawesi Utara.

\section{Hubungan ukuran utama dan GT kapal}

Hasil analisis data hubungan L dan kemampuan muat (GT) kapal pukat cincin dari data pada Tabel 1, membentuk rumus:

$$
\mathrm{GT}_{\text {pukat cincin }}=2,154 \mathrm{~L}^{0,043 \mathrm{~L}} \text {, dan nilai } \mathrm{r}=0,72 \text {. }
$$

Hubungan antara ukuran L dan GT kapal pukat cincin mengikuti hubungan regresi Geometric Fit, yang artinya pendugaan atau estimasi GT berdasarkan ukuran L kapal pukat cincin diperoleh model matematis dengan nilai regresi (b). Hubungan ini dapat digunakan untuk menjelaskan perubahan nilai GT pada setiap perubahan ukuran L kapal pukat cincin yang disubstitusikarf(Gambar 5).

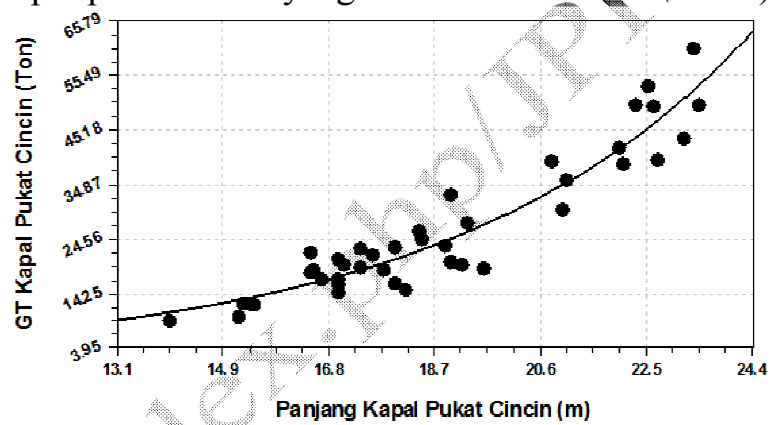

Gambar 5. Hubungan antara Panjang (L) dan kemampuan muat (GT) pada kapal pukat cincin kecil.

Figure 5. The relationship between Length $(L)$ and Gross Ton (GT) in a small purse seiner.

\section{KESIMPULAN}

Hasil penelitian menunjukkan adanya pola hubungan antar ukuran utama kapal pukat cincin mengikuti model persamaan $\mathrm{B}=1,855+1,149 \mathrm{~L}$, dan $\mathrm{r}=0,74 ; \mathrm{D}=-3,817+9,277 \mathrm{~L}$, dan $\mathrm{r}=0,70$. Begitu pula dengan pola hubungan antara ukuran Panjang (L) dan kemampuan muat (GT) kapal pukat cincin mengikuti model persamaan regresi Geometric Fit $\mathrm{GT}_{\text {pukat cincin }}=2,154 \mathrm{~L}^{0,043 \mathrm{~L}}$ dan $\mathrm{r}=0,94$.

\section{DAFTAR PUSTAKA}

Departemen Kelautan dan Perikanan Republik Indonesia. 2008. Himpunan Perundang-undangan Bidang Kelautan dan Perikanan.

Hyams D. 2009. Curve Expert v.1.40.

Marasut ThD. 2005. Analisis Karakteristik Teknis Kapal Pukat Cincin (Small Purse-Seiner) Pada Beberapa Daerah di SULUT Dengan Aplikasi Komputer. Fakultas Perikanan dan Ilmu Kelautan Universitas Sam Ratulangi, Manado.

Nomura M and Yamazaki T. 1977. Fishing Techniques (I). SEAFDEC. Japan International Agency. Tokyo.

Peraturan Pemerintah Republik Indonesia No. 51 Tahun 2002 Tentang Perkapalan. 
Sohariyanto dan Zarochman. 1999. Hubungan Ukuran Kapal Ikan Daya Penggerak dan Alat Tangkap. Direktorat Jenderal Perikanan Balai Pengembangan Penangkapan Ikan Semarang.
Suzuki O. 1980. Handbook for Scientists and Technologist, Training Departement Southeast Asian Fisheries Development Center.

Tabel 1. Hasil pengukuran ukuran utama dan GT kapal pukat cincin pada beberapa lokasi di Sulawesi Utara.

Table 1. Results of the main measurements and GT purse seiner in several locations in North Sulawesi.

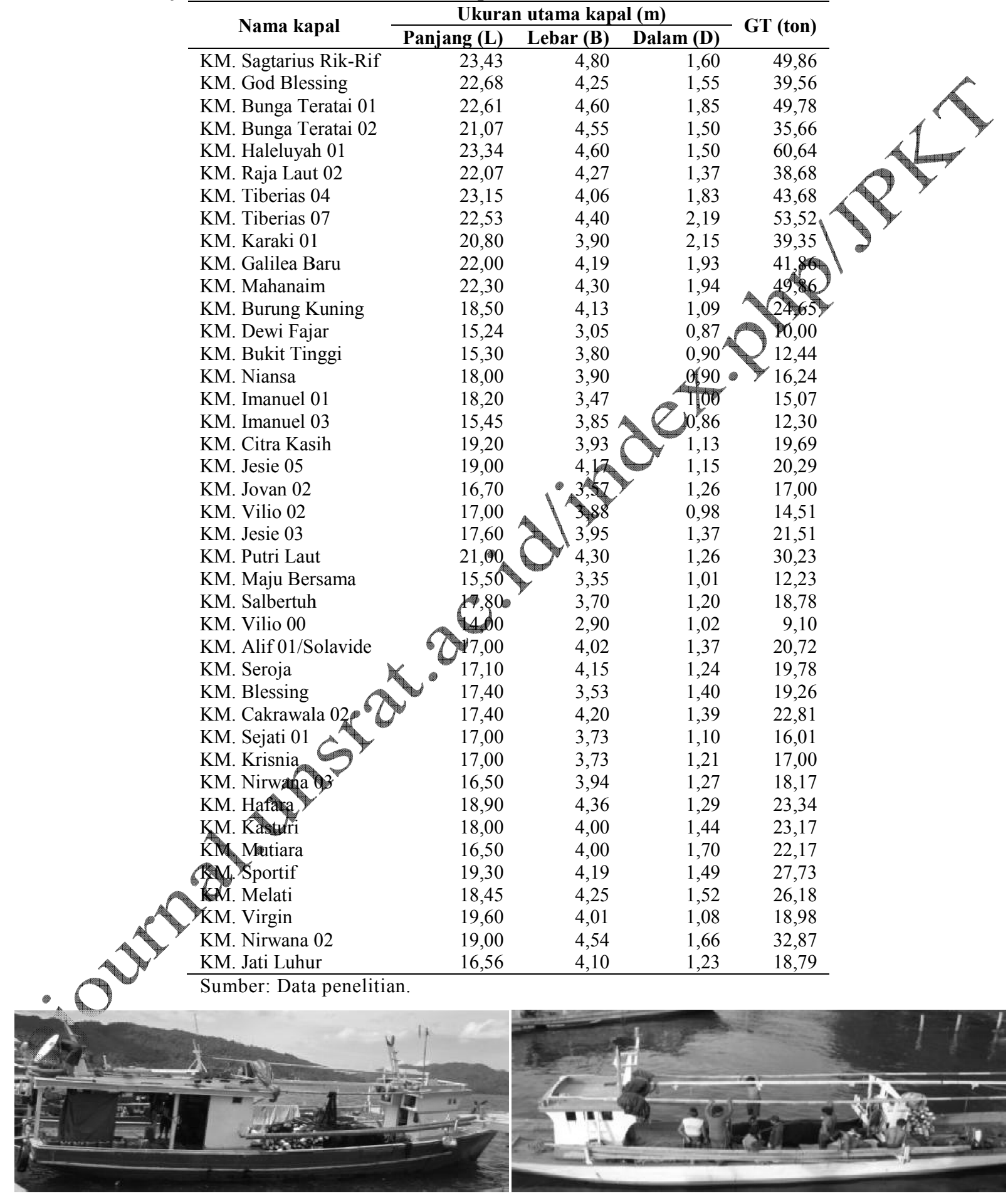

Gambar 6. Bentuk kapal pukat cincin kecil di Sulawesi Utara yang diteliti.

Figure 6. Form of small purse seiner in North Sulawesi. 